\title{
LA VIOLENCIA POLÍTICA EN COLOMBIA: JUSTICIA TRANSICIONAL EN EL MARCO DEL PROCESO DE PAZ ENTRE EL GOBIERNO SANTOS Y LAS FARC-EP*
}

\author{
Paulo Bernardo Arboleda Ramírez**
}

Fecha de recibido: 13 de agosto de 2013

Fecha de aprobado: 6 de noviembre de 2013

Artículo de reflexión

\begin{abstract}
Forma de citación: Arboleda, P. B. (2013). La violencia política en Colombia: justicia transicional en el marco del proceso de paz entre el Gobierno Santos y las FARC-EP. Revista Prolegómenos. Derechos y Valores, 16, 32, 49-68.
\end{abstract}

\section{Resumen}

En el mes de octubre de 2012 se iniciaron las negociaciones entre el gobierno del Presidente Juan Manuel Santos y la guerrilla de las Fuerzas Armadas Revolucionarias de Colombia (en adelante FARC-EP) en la ciudad de La Habana, Cuba, para buscar salidas que permitan la finalización definitiva del conflicto armado interno que ha azotado a Colombia por más de cuarenta años. La brújula de este nuevo intento de paz es una agenda presentada por el gobierno y que contiene cinco puntos que giran en torno a la redistribución de la tierra, al desarrollo agrícola, al fin de la guerra y del narcotráfico, y a los derechos a la verdad y a la oposición política. Para el desarrollo del texto se utilizó el método bibliográfico o documental que consistió en recopilar, organizar, sistematizar y analizar la información encontrada en libros, sentencias, artículos, etc., sobre la violencia política y la justicia transicional en Colombia. Como conclusión se establece que el Estado colombiano, especialmente su democracia, se encuentra en una profunda transformación que implicará asumir un costo político para obtener el tan anhelado derecho fundamental a la paz.

\section{Palabras clave:}

Conflicto político, negociaciones de paz, guerrilla de las FARC-EP, problemática agraria, intolerancia política.

\footnotetext{
Este artículo es un producto parcial del proyecto de investigación denominado: "Instituciones jurídico-constitucionales sujetas a reforma en el marco de la solución de conflictos políticos en Colombia", que se inició en el mes de febrero de 2013 y que finalizará en el mes de febrero de 2014. Este proyecto de investigación fue aprobado por el grupo de investigaciones Jurídicas y Sociales de la Facultad de Derecho de la Fundación Universitaria Luis Amigó, sede Manizales, cuyo investigador principal es el Dr. Paulo Bernardo Arboleda Ramírez y su asesor temático es el Dr. Milton César Jiménez Ramírez.

** Abogado, Universidad de Medellín, Especialista en Derecho Público, Universidad Externado de Colombia y Magíster en Derecho, Universidad de Medellín. Docente investigador de Tiempo Completo y Coordinador del semillero de investigación "Derecho y Conflicto Político" en la Facultad de Derecho de la Fundación Universitaria Luis Amigó, Manizales. Correo electrónico: pauloarboleda@gmail.com
} 


\title{
POLITICAL VIOLENCE IN COLOMBIA: TRANSITIONAL JUSTICE IN THE CONTEXT OF THE PEACE PROCESS BETWEEN THE SANTOS'S GOVERNMENT AND THE FARC-EP
}

\begin{abstract}
In October 2012, negotiations began between the government of President Juan Manuel Santos and the guerrillas of the Revolutionary Armed Forces of Colombia (FARC-EP onwards), in the city of La Havana, Cuba, to find solutions that allow the finalization of the internal armed conflict that has plagued Colombia for over 40 years. The compass of this new peace attempt is an agenda presented by the government, containing five points that revolve around land redistribution, agricultural development, the end of the war and drug trafficking, and rights to truth and political opposition. For the development of the text the bibliographic or documental approach was used, it consisted of collecting, organizing, systematize and analyze information found in books, statements, articles, etc.., on political violence and transitional justice in Colombia. As a conclusion, it will be said that the Colombian state, especially its democracy, is in a profound transformation that will involve taking a political cost to obtain the long-awaited fundamental right of peace.
\end{abstract}

\section{Keywords:}

Political Conflict, Peace Negotiations, Guerrilla of the FARC-EP, Agrarian Problematic, Politic Intolerance.

\section{VIOLÊNCIA POLÍTICA NA COLÔMBIA: JUSTIÇA DE TRANSIÇÃO NO CONTEXTO DA PAZ ENTRE O GOVERNO E SANTOS FARÇ-EP}

\begin{abstract}
Resumo
Em outubro de 2012, as negociações começaram entre o governo do presidente Juan Manuel Santos e os guerrilheiros das Forças Armadas Revolucionárias da Colômbia (FARC-EP em diante), na cidade de La Havana, Cuba, para encontrar soluções que permitam a finalização do mercado interno conflito armado que assola a Colômbia há mais de 40 anos. A bússola desta nova tentativa de paz é uma agenda apresentada pelo governo, que contém cinco pontos que giram em torno de redistribuição de terras, o desenvolvimento agrícola, o fim da guerra e tráfico de drogas, e os direitos à verdade e à oposição política. Para o desenvolvimento do texto foi utilizada a abordagem bibliográfica ou documental, que consistiu em coletar, organizar, sistematizar e analisar as informações encontradas em livros, depoimentos, artigos, etc., Sobre a violência política e justiça de transição na Colômbia. Como conclusão, será dito que o Estado colombiano, especialmente a sua democracia, está em profunda transformação que irá envolver a um custo político para obter o direito fundamental tão esperada paz.
\end{abstract}

\section{Palavras-chave}

Conflito político, Negociações de paz, Guerrilha das FARC-EP, Problemática agrária, Intolerância política. 


\section{INTRODUCCIÓN}

En Colombia el interés en los aspectos metodológicos referentes al análisis del conflicto político se ha acrecentado en el presente decenio, debido a la necesidad suscitada en el ámbito académico jurídico-político por complementar y orientar los estudios del derecho hacia una visión amplia del entorno social, político, económico y cultural; así como también por la necesidad de la acreditación que ha impuesto un aumento progresivo de la investigación jurídica, especialmente en los campos en donde se relacionan el Derecho y la Política (en el que se ubica, de manera convencional y algo arbitraria a la teoría política, el derecho constitucional, la sociología del derecho, la ciencia política, políticas públicas, etc.).

De este modo, para un estudio adecuado de las temáticas del derecho político resulta perceptible la superación de la visión legalista y, la aceptación de concepciones jurídicas tendientes a comprender el fenómeno de lo social, lo político y lo económico en sus diversas manifestaciones, como factores que repercuten en la constante dinámica de las normas e instituciones jurídicas.

De esta manera, un estudio riguroso del conflicto político en Colombia supone, como punto de partida, un detenido rastreo documental del texto jurídico ${ }^{1}$ acerca del contexto político, económico y social de una determinada época y asunto jurídico que se pretenda reconstruir y sistematizar. Con una de las intenciones del investigador jurídico-político de comprender los intereses que promovieron las diversas

Enumerar lo que puede ser un texto jurídico es tarea difícil, pero bien podría decirse, a manera enunciativa, que son textos jurídicos los siguientes: la normativa (incluye las constituciones, los códigos y las recopilaciones, etc.), los proyectos de ley y los debates parlamentarios o del legislador, los autos y las sentencias proferidas por jueces y magistrados, los textos de correcta aplicación de la norma, manuales de clase de derecho, la literatura reputada en su contexto como científica, los planes de estudio y formación de los abogados y los discursos forenses recogidos por cualquier medio. manifestaciones violentas que perduran en el tiempo.

Por tanto, si se procura concebir las transformaciones del conflicto político en Colombia desde los inicios de la República, pasando por la agudización del mismo durante el siglo XX, se hace indispensable consultar el material de estudio que contenga las condiciones de la sociedad en distintas épocas, que permita ofrecer explicaciones precisas del pasado del mundo jurídico para configurar el presente y el futuro de las muchas formas de expresión del derecho.

En este sentido, las actuales negociaciones de paz que se realizan en La Habana entre el Gobierno Santos y los voceros delas FARC-EP, no deben estudiarse de forma aislada o coyuntural; por el contrario, deben abordarse desde un modelo de lectura integral que atienda a las causas del conflicto político en aras de comprender el problema desde su estructura. Como resultado de esta tarea, se obtendrá la información pertinente que permita la formulación de soluciones integrales que cuenten con un alto porcentaje de éxito en su aplicación.

Para efectos del presente trabajo, no se reducirá el término paz a la "cesación del conflicto armado, abandono de las armas por parte de las organizaciones al margen de la ley e instauración del monopolio de la fuerza estatal" (Restrepo, 2006, p. 317). Esta observación tiene lugar, ya que el concepto de paz no se reduce exclusivamente a un proceso de desmovilización y entrega de armas, sino que va más allá, abarcando determinadas consideraciones económicas, políticas y sociales, que en su momento han sido calificadas como causantes del origen y del recrudecimiento de la violencia política en el país.

Ahora bien, hoy el Estado colombiano pasa por una profunda transformación; es en este contexto de reestructuración donde tiene lugar el desarrollo de una investigación sobre las instituciones jurídico-constitucionales sujetas a reforma en el marco de la solución de con- 
flictos políticos. Pero antes de identificar los contenidos normativos objeto de reforma constitucional, se hace necesario caracterizar los principales conflictos políticos que promueven la realización de una reforma constitucional en materia política y electoral.

Por consiguiente, se hará un estudio descriptivo y cronológico de los hitos o principales sucesos históricos de relevancia jurídico-política que han acaecido en el país desde inicios del siglo XIX hasta la fecha; esto con la finalidad de establecer si las situaciones que se viven en la actualidad pueden considerarse como consecuencias de estos eventos históricos (historia lineal y pervivencia) o como fenómenos recientes que no tienen relación con estos eventos histórico-políticos del país (historia no lineal o con ruptura).

Como se observa, la investigación encuentra su asidero en la necesidad de generar avances en el conocimiento, derivados de la interacción interdisciplinar de ciencias como el derecho y la ciencia política. Así, el presente artículo se justifica en la trascendencia de establecer, desde un análisis estructural y no coyuntural, un esquema de lectura riguroso que permita el estudio de la violencia política en Colombia desde variables tales como la cultura política de cada época, la realidad social y económica $y$, el contenido y el alcance de los acuerdos e intentos de acuerdos planteados como salidas a la confrontación armada con la guerrilla de las FARC-EP.

Para el desarrollo del texto, se entenderá por conflicto armado la inestabilidad de los escenarios político, social, militar y económico de un determinado Estado que se encuentra en una pugna permanente con un actor armado ilegal que pretende reemplazarlo en el ejercicio legítimo del poder. Estos conflictos políticos se originan, en una primera lectura, por la ausencia del Estado en gran parte del territorio del país, factor determinante para el encauzamiento ilegítimo de las denuncias sociales de los habitantes de aquellas zonas por parte de los grupos al margen de la ley. En consecuencia, estos actores armados ilegales, en la consecución de su objetivo de constituirse como Estado, despliegan sus acciones tanto en el plano militar como en el ideológico y económico.

Para ahondar en el concepto, el conflicto armado es "la lucha insurreccional llevada a cabo por organizaciones guerrilleras con el propósito de transformar revolucionariamente el orden social y el Estado que lo protege, y la repuesta estatal y paramilitar. Esta lucha no se libra exclusivamente en el plano de las armas. Los contendientes emplean tácticas y estrategias económicas, sociales, políticas y psicológicas" (Palacios, 2000, pp. 345-346).

Frente al conflicto armado, Diana Hoyos señala que este ejerce continua influencia sobre las estructuras y las funciones de las instituciones democráticas del país. Al respecto, se trae a colación el siguiente argumento:

El sistema democrático es desafiado constantemente por las prácticas de intimidación que los actores armados ejercen sobre los actores políticos y sociales y por las distintas formas de influencia y control sobre las instituciones, los gobiernos y la población. En este contexto es de esperar que el funcionamiento de las instituciones, los procesos electorales, los procesos participativos y las mismas formas de hacer política se redefinan, transformen o asuman lógicas particulares como consecuencia de la influencia y control de los actores armados en aquellos territorios donde han tenido una presencia permanente o incluso en aquellos que han constituido escenarios de disputa (2009, p. 14).

Ahora bien, como se mencionó, el texto que se presenta es el resultado parcial de un proyecto de investigación que será descriptivo cuando se dirija a establecer las estructuras del sistema de partidos políticos y del régimen electoral desde la expedición de la Constitución Política de 1991, pasando por el análisis de los actos legis- 
lativos 01 de 2003 y 01 de 2009, y será propositivo cuando se determinen las instituciones constitucionales objeto de reforma.

En este orden de ideas, para la ejecución del proyecto se han planteado cuatro objetivos específicos:

1. Identificar los elementos sobre los cuales se han estructurado las reformas políticoelectorales en Colombia desde 1991.

2. Identificar los principales conflictos políticos que promueven la realización de una reforma constitucional en materia política y electoral.

3. Establecer la compatibilidad de una justicia transicional con la reinserción política de los desmovilizados de las FARC-EP.

4. Establecer el alcance de una reforma electoral en el contexto de la reinserción. Este objetivo se orienta a elaborar una propuesta de reforma político-electoral integral para Colombia que contenga los elementos estructurales identificados durante el desarrollo de la investigación, en aras de la reestructuración viable del Estado y de la solución negociada del conflicto armado.

Cabe anotar que este artículo se enmarca en la ejecución parcial de los objetivos 2 y 3 . Pasando a los aspectos metodológicos, se menciona que se utiliza el método bibliográfico o documental; este método «consiste en la captación por parte del investigador de datos aparentemente desconectados, con el fin de que a través del análisis crítico se construyan procesos coherentes de aprehensión del fenómeno y de abstracción discursiva del mismo para así valorar o apreciar nuevas circunstancias» (Botero, 2003, p. 109).

Como se evidencia, los documentos y la bibliografía cobran gran importancia en la investigación documental, ya que no son simples listados de textos a ser consultados en una unidad documental (biblioteca, archivo, hemeroteca, etc.), sino que es necesario aplicar toda una técnica investigativa que consiste en organizar, seleccionar y relacionar, a través de un riguroso trabajo, la información que se encuentra en ellos. Por consiguiente, en la aplicación del método documental o bibliográfico, el investigador debe cuidarse de reunir, entre otros, los libros, documentos y archivos pertinentes al objeto del proyecto de investigación que se plantea; proceso anterior que se realiza a la selección de fuentes bibliográficas.

Asimismo, paralelamente a la aplicación del método bibliográfico, la investigación se desarrollará en un nivel de análisis de tipo jurídico-político, en el cual se considerará, tanto el aspecto normativo como el aspecto político que se encuentran implícitos en una reforma político-electoral en el marco de la solución de conflictos políticos.

De esta manera, la estructura del presente artículo inicia con una caracterización de la violencia política del país desde los primeros días de vida republicana en el siglo XIX hasta el surgimiento de la guerrilla de las FARC-EP. En este punto se indagará por las causas de la agudización del conflicto armado interno a mediados del siglo XX; posteriormente, se enunciarán los anteriores intentos de negociación de paz entre el gobierno colombiano con la guerrilla de las FARC-EP; continúa con un análisis de las actuales negociaciones de paz que se realizan desde octubre de 2012 en La Habana entre el gobierno del presidente Santos y las FARC-EP ; finalmente, se presentarán las conclusiones de las temáticas tratadas durante el desarrollo del artículo.

\section{LA VIOLENCIA EN COLOMBIA: ¿UNA CONSTANTE EN LA HISTORIA POLÍTICA DEL PAÍS?}

Para iniciar con la caracterización de la violencia política en Colombia, es importante formular la siguiente pregunta: ¿cuál es la relación temporal y espacial que permite comprender 
los acontecimientos políticos en la Colombia contemporánea desde el análisis del fenómeno de la violencia durante los siglos XIX y XX?

Para contestar a esta pregunta se debe acudir a un estudio interdisciplinario que abarque las ciencias o las disciplinas del Derecho, la Ciencia Política, la Sociología y la Historia, en aras de la rigurosidad en la investigación. En ese sentido, el tiempo y el espacio se configuran como factores determinantes de una sociedad, delimitando sus características y rasgos históricos, es decir, existe una interacción vital entre las dinámicas sociales bajo las cuales se desempeñan los individuos con los factores tiempoespacio; de tal interacción deviene la identidad propia de una sociedad.

Por tanto, si se quiere comprender las formas de vida de un grupo de individuos organizados en comunidad, se debe analizar detalladamente su historia para dar prelación a las reflexiones estructuradas desde el espacio-tiempovital. Por ende, un adecuado estudio acerca de la violencia en Colombia debe partir desde el análisis de estas categorías para su cabal desarrollo.

De esta forma, es necesario remontarse a los sucesos políticos del país más relevantes durante los siglos XIX y XX con el objeto de contextualizar y comprender los diversos acontecimientos que dieron lugar al surgimiento de los actuales problemas sociales, políticos y de variada índole que afectan la institucionalidad colombiana. En fin, se pretende brindar los elementos necesarios para analizar las agendas, los acuerdos y las consecuencias que puedan resultar de las actuales negociaciones de paz con la guerrilla de las FARC-EP.

Ahora bien, a continuación se hará una breve descripción cronológica de los principales hitos o eventos histórico-políticos que han tenido lugar en el país desde inicios del siglo XIX.

Así las cosas, las armas y el poder han atravesado la historia política del país desde los primeros días de vida republicana; como resultado, en el siglo XIX se presentaron 11guerras civiles o conflictos internos (Tirado, 2007), las cuales se caracterizaron por gestarse al interior de los partidos políticos en el marco de la pugna por la obtención del poder.

En síntesis, fue un siglo marcado por la búsqueda constante de un modelo de Estado y de un régimen de gobierno, mediante batallas tanto en el plano ideológico como armado; batallas motivadas en las diferencias ideológicas entre centralistas y federalistas que fundamentaron las plataformas programáticas, tanto del Partido Liberal como del Partido Conservador.

Para finalizar este breve recuento de los hechos históricos relevantes de este siglo, no se puede dejar de mencionar que entre los años 1899 y 1902 se desarrolló la última guerra civil entre liberales y conservadores, conocida como la "Guerra de los mil días», en la que murieron más de cien mil personas y llevó a la separación de Panamá del Estado Colombiano.

En cuanto al contexto político de la primera mitad del siglo XX, se resalta la hegemonía del Partido Conservador durante las tres primeras décadas y, por la construcción de la denominada «República Liberal» desde 1930 hasta 1946.

De este modo, en la década de los treinta la violencia surgió como consecuencia del levantamiento de armas de los campesinos motivados por la marcada tendencia latifundista de repartición de la tierra en la época (Legrand, 1986, pp. 97-110). En la República Liberal, el Partido Liberal aprovechó el desprestigio institucional que sufrió el movimiento Conservador, en razón a varias matanzas dirigidas por el gobierno contra organizaciones obreras y estudiantiles, en particular la matanza de las bananeras en el año de 1928 en la región del Magdalena Medio.

Así, los liberales guiaron los destinos de la patria por un período de dieciséis años, los necesarios para que el descontento de la población se orientara hacia la consecución de una comple- 
ja reforma agraria, a la que los terratenientes pusieron obstáculos, justificados en la inconveniencia que les crearía para la acumulación de capital y el mantenimiento de su elevado nivel de vida. Se debe tener en cuenta que la mayor parte del territorio era rural, que sus habitantes eran campesinos sin tierra y agricultores desplazados que no podían sembrar sus cultivos (en esta época se inicia el proceso de desplazamiento de habitantes del campo a la ciudad).

En este contexto, los esfuerzos de algunos gobiernos liberales no llegaron a fructificar aunque se hayan traducido en leyes. Tal es el caso del gobierno de Alfonso López Pumarejo, llamado de la "Revolución en Marcha", quien en1936 presentó en el Congreso de la República la llamada Ley 200 referente al régimen de tierras, al tiempo que se reformó la Constitución en materia de la concepción de la propiedad privada con función social.

En concordancia con lo anterior, la situación coyuntural de la Ley 200 de 1936 estuvo influenciada por una alta presión de los campesinos, y por la necesidad de una pronta intervención del Estado en los conflictos que ya se presentaban entre pequeños colonos y terratenientes por la posesión de hectáreas que los primeros habían destinado a la producción. Con esta Ley se pretendía dar un impulso sustancial a la utilización económica del suelo, clarificar los derechos de propiedad y posesión sobre baldíos, y encuadrar los conflictos agrarios a un nuevo orden jurídico, a través de la jurisdicción del Estado.

Como se observa, la Ley de tierras fue un intento para neutralizar las protestas rurales que se iniciaron en los años veinte, en particular el mencionado episodio funesto de la masacre de las bananeras en 1928, en la cual murieron centenares de trabajadores quienes exigían mejores condiciones laborales (Sánchez \& Peñaranda, 1986).

Al respecto, Darío Mesa menciona que en la estructura agraria del país «prevalecía un grado precario de división del trabajo por parte de los principales dueños de la tierra, constituyendo, ésta una causa de retraso» (Mesa, 1972, p. 24). Además, la ocupación de la tierra se conformaba del latifundio y del minifundio campesino, resaltándose que «en los latifundios se utilizaban distintos modelos de trabajo en los que se hacía uso de mano de obra indígena, mestiza y negra, con una fuerte sujeción del campesino sin tierra» (Tirado, 1998, p. 57). Hechos que generarían el inconformismo generalizado de estos grupos sociales.

Este panorama de inequidad en la distribución de las tierras fue el factor detonante del descontento de los campesinos colombianos, quienes empezaron a manifestarse recurriendo a las armas para exigir soluciones de parte del Estado.

En este orden de ideas, la Ley de Tierras de 1936 no logró establecer mecanismos reales de distribución de las tierras, hecho que se tradujo en el aumento de los problemas de violencia en las zonas rurales del país y en la creación de imaginarios sociales de justicia privada (coloquialmente se le denomina justicia de propia mano) que extendió la polaridad bipartidista desde el plano político hacia el plano de la violencia armada bajo las banderas rojas y azules (El Partido Liberal se representa con el color rojo, mientras que el Partido Conservador con el color azul).

Al finalizar el período denominado como «La República Liberal» en 1946, terminan los gobiernos liberales y se elige como Presidente de la República al político conservador Mariano Ospina Pérez, quien ejerció sus funciones hasta 1950. Bajo este gobierno, el 9 de abril de 1948, asesinan en la ciudad de Bogotá al candidato presidencial por el Partido Liberal Jorge Eliécer Gaitán (Sánchez, 1983). Este magnicidio significó el recrudecimiento de la violencia política a lo largo de todo el territorio nacional, empezando por las destrucciones y los centenares de personas que perdieron la vida en «El Bogotazo" a causa de los incontrolables disturbios que se presentaron. 
Así pues, la violencia tomó otros matices, dejando atrás las luchas de los campesinos alzados en armas en pro de sus derechos hacia un conflicto político bipartidista excluyente de cualquiera otra posición ideológica, que no solo se desarrolló en la arena político-electoral sino también en el plano armado mediante la conformación de grupos al margen de la ley en muchos de los municipios del país.

Frente a esta problemática, Mabel Londoño sostiene:

Esta confrontación partidista fue llevada a sus extremos de mayor violencia en la época conocida como la Violencia (19481953), cuando los dos partidos tradicionales o, como lo señala Daniel Pécaut (2003a, p. 34), las dos subculturas políticas existentes en el país, conformadas, a su vez, por élites políticas, se enfrentaron por el poder político, la burocracia estatal y la apropiación de tierras, arrastrando a las masas populares apasionadas que no comprendieron, sino hasta muy tarde, que los ideales de la guerra eran ajenos a sus intereses sociales (2012, pp. 9-10).

Es así como el trasegar político del país se ha caracterizado por la lucha constante de ostentar el poder, ya sea para mantener intereses de grupos económicos de gran influencia o para hacer oposición armada o pacífica para la desarticulación del sistema político vigente. Lo anterior es clara muestra de la intolerancia y la supresión del derecho a la diferencia de mediados del siglo XX en Colombia. No es de asombrar que este conflicto político aún persista, pues se identifica que sus orígenes responden a dos problemas estructurales sin solucionarse relacionados con la distribución y el uso de la tierra, y la exclusión política.

Posteriormente, en 1950 es elegido como Presidente de Colombia el conservador Laureano Gómez, en cuya corta gestión (dos años como Presidente, pues en 1952 es reemplazado por Rafael Urdaneta debido a su mal estado de sa- lud) se conformaron grupos subversivos en las zonas rurales del país en torno a los dos partidos políticos del momento. De este modo, la violencia partidista desembocó en una situación de ingobernabilidad e inseguridad.

Entre estos grupos que surgieron en la década de los cincuenta se encuentra «Los pájaros», dirigidos por León María Lozano (alias el Cóndor), un grupo armado al margen de la ley que luchaba bajo las banderas del Partido Conservador con los objetivos de asesinar a las personas de orientación liberal y fortalecer los valores cristianos-católicos. En este absurdo conflicto murieron más de trescientos cincuenta mil personas, generando una fuerte crisis en el orden público del país (Tirado, 2001).

Asimismo, se resalta la aparición de las guerrillas liberales de los Llanos orientales auspiciadas por el Partido Liberal con el objetivo de defenderse de las incursiones militares ordenadas por el Gobierno Gómez y de los homicidios en masa ejecutados por «Los Pájaros». Al respecto, Medina señala:

Con la aparición de la guerrilla liberal la violencia adquirió el carácter de una guerra civil en la que la población campesina en armas, dirigida regionalmente por el Partido Liberal, se enfrentaba al terrorismo de Estado agenciado por el gobierno de Laureano Gómez y Roberto Urdaneta Arbeláez.

Los grupos guerrilleros se establecieron en regiones que por sus características geográficas, sociales y políticas les permitían subsistir y adelantar la lucha de resistencia con grandes posibilidades de éxito. Se tuvo en consideración al determinar los lugares de ubicación de la guerrilla liberal, que las condiciones topográficas fueran favorables para el desarrollo de ese tipo de lucha, que existiese un relativo aislamiento de los centros de poder, que los habitantes de la región estuviesen unidos por un cierto grado de identificación política y que, en alguna 
medida, los propietarios de grandes extensiones fuesen tolerantes con la presencia de grupos armados en sus territorios (2010, p. 124).

Luego en 1953 el General Gustavo Rojas Pinilla propicia un golpe de Estado al gobierno conservador $y$, por ende, se toma el poder (con el apoyo del Partido Liberal, la élite económica y la cúpula militar) con la finalidad de recuperar el orden público. En tal sentido, Pécaut explica que

(...) sostenido por la casi totalidad de las élites, preocupadas por el peligro de que la violencia escapara de su control, el general Rojas Pinilla intentará, a partir de 1955, recurrir a ciertos ingredientes de populismo. Imitando a su vez a Perón, invoca al pueblo para consolidar su legitimidad, se esfuerza por hacer de su hija, María Eugenia, una especie de Evita encargada de una política simbólica de filantropía, preconiza una «tercera vía» de desarrollo. El proyecto no podrá ir muy lejos. Por un lado, el general Rojas Pinilla, que participó en la violencia conservadora, emprende al mismo tiempo la tarea de reducir por la fuerza los focos campesinos de resistencia suscitados por el Partido Comunista, lo que quita a su proyecto gran parte de credibilidad. Por otro lado y sobre todo, las élites no tardan en manifestar que no están dispuestas a tolerar la emancipación del que consideran como su criatura: el héroe de 1953 se ve pronto denunciado como un «dictador» (2001, pp. 73-74).

Así pues, la dictadura de Rojas logró el control del territorio y una aparente paz; trajo desarrollo tecnológico; invirtió en infraestructura; reconoció el derecho al voto a las mujeres; entre otros aspectos positivos. Pero todos estos avances se opacaron con las órdenes emitidas por Rojas, de asesinar a un centenar de estudiantes que se manifestaban de manera pacífica en la capital; suceso que le representó al gobierno el retiro del apoyo político del Partido Liberal.
Ante esto, en 1957 una Junta Militar administró el país hasta 1958, en donde se crea el «Frente Nacional».

El «Frente Nacional» tuvo como protagonistas al Partido Liberal y al Partido Conservador (Hoyos, 2007), colectividades que se alternaban cada cuatro años el poder político del país. Este acuerdo inició en 1958 y debía terminar en 1970, pero se extendió hasta 1974. Posteriormente, en este año el Partido Liberal ostentó el poder presidencial hasta 1998, con la excepción de que el Partido Conservador obtuvo la presidencia de la República en el período comprendido entre 1982 a 1986 (Gobierno Betancur $)^{2}$. No obstante, en ciertos aspectos como la distribución burocrática del Estado se mantuvo el «Frente Nacional» (Hartlyn, 1993).

Bajo esta óptica,

La característica central del sistema del Frente Nacional es que se trataba de un mecanismo para evitar pero no para innovar; para mantener pero no para avanzar; para evitar que un partido tomara la primacía sobre el otro, fuese cual fuese su respaldo popular; para impedir que en el panorama político pudieran aparecer institucionalmente otras fuerzas concurrentes; para lograr un consenso, que a la postre se volvió paralizante, a partir de la disposición por la cual se exigía que las decisiones en las corporaciones públicas fueran tomadas por mayorías de las dos terceras partes; y para impedir que el mismo mecanismo de

2 En contraste, Carlos Ariel Sánchez señala que "la colaboración prolongada entre los partidos podría llevar a hablar de Partido Único del Frente Nacional. Único, en tanto excluyente. Este análisis fue propuesto en varias ocasiones, el cual no puede ser históricamente compartido, aunque se hayan aceptado varios argumentos. No es posible creer que los dos partidos se hayan fusionado sino que sencillamente sus frontera ideológicas se borraron; es decir, que el Frente Nacional conservatizó al país, no solamente durante los 16 años previstos como consecuencia del pacto de Benidorm, sino también durante los mandatos de Alfonso López, Julio Cesar Turbay y Belisario Betancur" (Sánchez, 2006, p.102). 
cambio institucional que había sido aplicado para salir del embrollo social que en ese momento se vivía, pudiera ser puesto en práctica de nuevo (Tirado, 2001, p. 398).

Se reitera que el Frente Nacional estableció un sistema cerrado que excluyó la participación activa de otras ideologías en la "democracia» de mediados del siglo XX. Hecho que impidió que otros movimientos sociales y políticos contaran con los espacios adecuados de participación en la escena político-electoral. Al respecto, se observa el siguiente argumento:

Si bien las distintas fuerzas sociales se hayan enmarcadas en la dinámica de los partidos tradicionales, contribuyendo al mantenimiento del bipartidismo, el Frente Nacional produjo un sentimiento de exclusión y apatía debido a que limitó la participación popular no mediada por los partidos tradicionales, lo que empezó a gestar importantes fuerzas opositoras y un crecimiento de la abstención (Gutiérrez, 2007, pp. 107-109), totalizada para este período en un cincuenta por ciento (Londoño, 2012, pp. 12-13).

En coherencia con los párrafos precedentes, los sucesos históricos mencionados son clave para estudiar no solamente los procesos socio-políticos que se dieron en la segunda mitad del siglo $\mathrm{XX}$, sino también los que se han desarrollado desde los primeros años del siglo XXI hasta el día de hoy; por ejemplo, se identifica que bajo el funcionamiento del Frente Nacional, surgen en 1964 los grupos guerrilleros de las FARC-EP , el Eln y el Epl (Fals \& Umaña, 2005) como reacciones violentas armadas a la inequidad en cuanto a la distribución de la tierra y a la concentración del poder político en pocas personas (supresión del derecho a la diferencia y a la oposición). Asimismo, en 1970 surge el Movimiento 19 de Abril como respuesta al fraude electoral en las presidenciales.

Sobre la problemática, se trae a colación un apartado del estudio realizado por Londoño:
El Frente Nacional logró desactivar las violentas manifestaciones partidistas, no obstante, y pese a la acción emprendida por los gobiernos para neutralizar el auge de los movimientos insurgentes de izquierda, aparecieron los grupos guerrilleros más importantes como es el caso de las Fuerzas Armadas Revolucionarias de Colombia (FARC), el Ejército de Liberación Nacional (ELN), el Ejército Popular de Liberación (EPL) y el Movimiento 19 de abril (M-19), que justificaban su accionar en la convicción de que las vías legales de acceso a la escena política se encontraban herméticamente cerradas. Esta situación generó una nueva tipología de violencia debido a que los protagonistas ya no eran los miembros de los partidos políticos tradicionales sino las guerrillas que se alzaron en armas contra el Estado (2012, pp. 13-14).

Frente a este sistema político excluyente, y dando un gran salto temporal, la Asamblea Nacional Constituyente de 1991, con respecto al debate sobre el sistema de partidos políticos conveniente para la institucionalidad del país, se orientó a establecer un sistema político participativo para permitir que nuevas fuerzas políticas ingresaran en el escenario electoral y, por tanto, destruir los cimientos del modelo bipartidista que venía imperando desde los primeros años de vida republicana en el siglo XIX y, que se había cerrado absolutamente a cualquiera otra ideología política a partir de la creación del «Frente Nacional» en 1958.

\section{ENUNCIACIÓN DE LOS INTENTOS DE NEGOCIACIÓN DE PAZ ENTRE EL GOBIERNO COLOMBIANO CON LA GUERRILLA DE LAS FARC-EP}

Va casi medio siglo de confrontación armada con las guerrillas, lapso de tiempo en el cual las estructuras del Estado se han debilitado hasta el punto de llegar a encender las alarmas, en más de una ocasión, debido a las múltiples acciones armadas que han buscado el colapso 
del andamiaje institucional; entre las que se recuerda, la agudización de las hostilidades ${ }^{3}$ por parte de la guerrilla de las FARC-EP dirigidas hacia la sociedad civil durante los últimos meses del gobierno Pastrana (en particular los meses de enero y febrero de 2002).

No obstante, desde la década de los ochenta los diferentes gobiernos han realizado intentos por encontrar una salida negociada al conflicto con este grupo al margen de la ley. En este sentido, se hará a continuación una enunciación de los anteriores intentos por lograr la paz con las FARC-EP, lo que permitirá la comprensión de los actuales diálogos que se adelantan en La Habana (el análisis de este proceso de paz se realiza en el siguiente acápite).

Así pues, en las negociaciones de paz que se adelantaron en 1985 entre el gobierno de Belisario Betancourt y los grupos guerrilleros de las FARC y el ELN , se destacó la promoción de espacios de participación político-electoral dirigidos hacia los integrantes de estos movimientos insurgentes quienes se acogieron a esta salida política del conflicto. Este acuerdo político se materializó con la creación de una colectividad política a la que se le denominó como la «Unión Patriótica» (UP); coalición electoral conformada por los desmovilizados de estos grupos guerrilleros y por los militantes de los movimientos de izquierda del país que habían estado marginados de la participación política a causa del Frente Nacional.

Sobre el tema, Romero señala:

Es cierto que la «combinación de todas las formas de lucha»-electoral, armada y movilización social- de la guerrilla, en especial de las FARC, no contribuyó en nada a la propuesta de paz del Presidente Betancur

3 Sobre las hostilidades por parte de la guerrilla de las Farc-EP durante los últimos meses del gobierno Pastrana, se subrayan los atentados mediante la utilización de explosivos en las diferentes ciudades del país y que dejaron decenas de muertos; el secuestro de políticos; y los ataques indiscriminados dirigidos a muchos municipios del país como, por ejemplo, la masacre perpetrada en Bojayá, Chocó, el 12 de mayo de 2002. en 1982, pero tuvo un efecto aún más nocivo en las posibilidades de reconciliación la estrategia contrainsurgente de eliminar a los frentes electorales surgidos de la guerrilla, como resultado de los acuerdos de paz. Al aniquilar a la Unión Patriótica, UP, coalición electoral que incluía a sectores progresistas, al partido comunista, $y$ a miembros de las FARC, el grupo insurgente más fuerte, lo mismo que a los movimientos regionales de otras tendencias de la izquierda, la reacción en contra de las nuevas agrupaciones acabó con la posibilidad de debilitar a los "guerreristas" de la guerrilla, al impedir que los partidarios de formas legales de participación pública pudieran cosechar los beneficios de una movilización política exitosa. Esa estrategia también dio desde la autoridad una señal que legitimó el uso de la violencia como forma de resolución de conflictos, hecho que ha estado en la base de la crisis de derechos humanos en la que ha vivido el país desde hace dos décadas. Así, a través del terror, los paramilitares y sus colaboradores civiles y estatales comenzaron una carrera como actores decisivos en las posibilidades de una negociación de paz (2000, p. 335).

Es en este contexto de apertura política y de negociación de paz con las guerrillas, en el que surgieron los grupos paramilitares durante la década de los ochenta. No obstante, paralelamente a este evento democrático, no puede olvidarse que a finales de la década de los setenta empezó a consolidarse el negocio de la producción y de la exportación de drogas ilícitas en el país; fenómeno del narcotráfico que trajo consigo, particularmente durante la década de los ochenta, la pérdida de los valores de la sociedad, el terrorismo, las desapariciones, los homicidios y la financiación de otros grupos armados ilegales conocidos como paramilitares, especialmente las Autodefensas Unidas de Colombia (AUC), para combatir a las guerrillas.

Por consiguiente, tanto el narcotráfico como una democracia electoral local, sin las debidas 
cortapisas, fueron detonantes de la violencia paramilitar en el país. Al respecto, se encuentra:

Los riesgos de una posible democratización provocaron la reacción negativa de élites regionales ligadas a los partidos liberal y conservador -pero principalmente al primero- frente a la posible incorporación a los diferentes sistemas políticos locales de los antiguos insurgentes, y con esto, la inclusión de grupos sociales hasta ese momento marginados del debate público (Romero, 2000, pp.333-334).

A renglón seguido, Romero manifiesta que

(...) la apertura política y las negociaciones de paz, combinadas con la descentralización y la elección de alcaldes, pusieron en riesgo -o al menos esa fue la percepción de los liderazgos tradicionales- los equilibrios políticos establecidos en las regiones en donde la guerrilla y sus aliados electorales habían logrado influencia. Pero además, esa misma apertura institucional y del régimen también ofreció posibilidades para la acción colectiva de grupos y sectores sociales que habían sido marginados por la forma limitada del sistema de representación electoral, y el aplastante dominio de las élites locales y rurales en la política regional y nacional. Los líderes y activistas que encabezaron esas movilizaciones han sido las principales víctimas de la crisis de derechos humanos de las dos últimas décadas (2000, pp. 334-335).

Otro intento fallido por obtener la paz se ubica entre los años de 1991 y 1992; estos encuentros entre el Gobierno de Cesar Gaviria y la Coordinadora Guerrillera Simón Bolívar -de la que formaban parte las FARC-EP, el ELN y el EPL - se realizaron en Tlaxcala (México) y en Caracas (Venezuela). Estos acercamientos hacia la paz fueron suspendidos después de que el EpL secuestrara al exministro Argelino Durán Quintero (quien murió en cautiverio después de presentar serios problemas cardiacos).
Ahora bien, bajo el Gobierno Pastrana, y en el marco de las negociaciones de paz instaladas en 1999, se crea la zona de despeje militar en el Municipio de San Vicente del Caguán, que contó con más de cuatro mil kilómetros de extensión destinados para el asentamiento de la guerrilla de las FARC-EP. Así las cosas, este intento de paz se caracterizó, por un lado, por la creación y la aplicación del Plan Colombia (financiado por el gobierno de los Estados Unidos de Norteamérica), con miras a la reestructuración de las fuerzas armadas del país; por otro lado, paradójicamente, se caracterizó por el fortalecimiento de la guerrilla de las FARC-EP, tanto en el ámbito nacional como en el internacional.

Estas negociaciones de paz fueron terminadas unilateralmente por el Gobierno Pastrana el 24 de febrero de 2002, debido al secuestro de un avión por parte de las FARC-EP ese mismo día. Se recuerda, entonces, que el Presidente Pastrana anunció ante los medios de comunicación el cierre de la puerta de la paz y, de contera, clausuró la zona de distención ordenando la llegada inmediata de las fuerzas militares al Municipio de San Vicente del Caguán.

En los meses posteriores a este anuncio, el candidato presidencial Álvaro Uribe Vélez remonta en las encuestas superando al candidato liberal Horacio Serpa. Es así como Uribe centró su campaña presidencial en formular una política orientada hacia la recuperación de la soberanía y la terminación definitiva del grupo guerrillero de las FARC por medio del uso legítimo de la fuerza del Estado; posteriormente, en mayo de 2002, Álvaro Uribe es electo como Presidente de la República de Colombia, tomando posesión del cargo el 7 de agosto del mismo año en un ambiente generalizado de esperanza -por parte de la mayoría de la población colombiana-en la ejecución exitosa de la política de «Seguridad Democrática». Con referencia a esta política bandera del gobierno Uribe, se menciona el hecho de que se invirtió gran parte del presupuesto del país en fortalecer a las fuerzas armadas para contrarrestar los ataques 
de la guerrilla de las FARC-EP. En ese sentido, sin entrar a evaluar detenidamente las actuaciones del gobierno Uribe, se resalta que se recuperaron muchos de los territorios que se encontraban bajo el control de este grupo guerrillero y se dieron bajas importantes al secretariado de esta organización insurgente.

De este modo, se hace notorio que durante los dos períodos presidenciales de Álvaro Uribe (2002-2006; y, 2006-2010), el discurso se estructuró en recuperar el orden en el país a través del despliegue de las fuerzas armadas para encontrar la libertad (mensaje que hacía alusión al lema del escudo patrio «Libertad y Orden»); así pues, se anuló cualquier intento de negociación o salida política con las FARC-EP.

Sin embargo, en este gobierno se firmaron acuerdos de paz con el grupo paramilitar denominado las Autodefensas Unidas de Colombia (AUC); estos acuerdos fueron respaldados por un marco jurídico a través de la expedición de la Ley 975 de 2005 o también conocida como la Ley de Justicia y Paz (este marco jurídico permitió establecer una justicia transicional para adelantar las investigaciones y los juicios de los desmovilizados de este grupo al margen de la ley).

Como ha explicado Uprimny, los procesos de paz o de justicia transicional deben plantearse, ya sea para

(...) llevar a cabo una transformación radical del orden social y político de un país, o bien para reemplazar un estado de guerra civil por un orden social pacífico, o bien para pasar de una dictadura a un orden político democrático. Especialmente cuando se trata de transiciones cuyo objetivo es dejar atrás un conflicto armado y reconstituir el tejido social, dicha transformación implica la difícil tarea de lograr un equilibrio entre las exigencias de justicia y paz, es decir, entre los derechos de las víctimas del conflicto y las condiciones impuestas por los actores armados para desmovilizarse (Uprimny, 2005, p. 4).
Retomando el tema referente a las negociaciones de paz realizadas entre los diferentes gobiernos con las FARC-EP, desde finales del año 2012 se hizo de conocimiento público, otro intento de salida política al conflicto armado liderado por gobierno Santos.

En este orden de ideas, más de nueve gobiernos han intentado solucionar el conflicto interno colombiano sin lograr avances significativos en esta gran empresa de la paz; no obstante, los gobiernos de Virgilio Barco y de César Gaviria tuvieron éxito parcial en sus respectivas negociaciones de paz con la guerrilla del M-19. Por otra parte, también se subraya que en los gobiernos de Álvaro Uribe se logró la desmovilización de los integrantes de las Autodefensas Unidas de Colombia, pero sin lograr avances estructurales conducentes a la finalización definitiva del accionar paramilitar.

En relación con este punto, Angarita \& Gallo plantean que

(...) en las últimas décadas, el conflicto armado colombiano ha tenido cambios significativos y diversos tratamientos: diálogos de paz y su fracaso en el gobierno de Andrés Pastrana; en el gobierno de Uribe, desde sus inicios, la estrategia de derrotar militarmente a la insurgencia, materializada en la política de Seguridad Democrática; los acuerdos, alianzas, negociaciones y rupturas, entre agentes estatales y privados (con paramilitares); la Ley de Justicia y Paz, entre otros. Estos cambios han reconfigurado las relaciones y confrontaciones de los actores armados en el conflicto (2012, p. 214).

Asimismo, se comparte que

(...) desde el Estado no ha existido unidad de criterios en el tratamiento del conflicto armado; así, por ejemplo, dentro de nuestro período de estudio (1998-2009), se han presentado diversas posturas por parte del gobierno nacional; desde llamados a la desmovilización de los combatientes con 
ofertas de beneficios jurídicos y sociales, pasando por aceptar una mediación internacional bajo ciertas condiciones (Pastrana) hasta, incluso, la postura más radical de negar la existencia de un conflicto armado en el país (Uribe), llegando a considerar como una concesión a la insurgencia o una justificación del mismo, el empleo de la denominación "conflicto armado" o similares, para referirse a las formas de violencia padecida por los colombianos desde hace varias décadas (Angarita \& Gallo, 2012, p. 214).

\section{ANÁLISIS DE LAS NEGOCIACIONES DE PAZ QUE SE REALIZAN EN LA HABANA}

En este acápite se realizará un análisis de las negociaciones de paz que actualmente se adelantan entre el gobierno Santos y el grupo guerrillero de las FARC-EP. Es de anotar que estos diálogos responden a solucionar

(...) la realidad política colombiana del presente, atravesada por un conflicto armado persistente y continuado, aunado en torno a la lucha por la construcción del Estado Nacional: con una soberanía puesta en vilo por actores armados de diferente signo y por la gran delincuencia organizada; con una sociedad civil desconfiada y atemorizada que sólo acierta demandar orden, seguridad y garantías para sus vidas y sus bienes, evoca de manera inmediata al viejo filósofo de Malmesbury, que construyó sobre la pasión del miedo, el gran edificio de la política moderna (Uribe, 2002, p. 26).

Como se aprecia, el conflicto interno colombiano se ha perpetuado por ilegales que creen tener la verdad absoluta; en consecuencia, se puede afirmar que el Estado colombiano se encontraba derrotado por las FARC-EP bajo el gobierno Pastrana (1998-2002); posteriormente, bajo los gobiernos de Uribe (2002-2010), el Estado logró recuperar su presencia en gran parte del territorio y avanzó en el plano militar para debilitar a esta guerrilla, pero fracasó en el aspecto social; y, bajo el gobierno Santos, se observa que en el plano militar la guerrilla aún se encuentra debilitada, pero por arrogancia quieren salir de la guerra como vencedores $y$ no como vencidos.

Así pues, las dos partes de este nuevo proceso de paz (gobierno y la guerrilla de las FARC-EP) llegan a la mesa con la convicción política y la seguridad jurídica de lograr acuerdos sobre cada uno de los cinco puntos de la agenda propuesta por el gobierno Santos, con el propósito de darle fin a un largo conflicto armado de más de cuarenta años que ha dejado a su paso miles de muertos, centenares de personas secuestradas y de familias padeciendo el dolor de la guerra, y decenas de municipios destruidos por las tomas armadas por parte de la guerrilla de las FARC-EP . Las preguntas que surgen al respecto son las siguientes: ¿̇se obtendrá la paz definitiva en La Habana? o ¿̇erá otra negociación política frustrada como las de la década de los ochenta y la del gobierno Pastrana?

Ahora bien, para iniciar con el análisis de las negociaciones de paz que se realizan en La Habana entre el gobierno Santos y las FARC-EP, se mencionarán los cinco puntos de la agenda con la finalidad de brindar claridad al lector acerca de las estructuras que soportarán el peso de la construcción de la paz y, por ende, de un país tolerante y dispuesto al debate de las ideas que enriquezcan la maduración y la consolidación de la democracia.

1. Desarrollo rural. Este punto consiste en la tarea del Estado de llevar desarrollo a las regiones del país, que por tantos años han padecido los efectos del conflicto bajo la mirada impávida de los diferentes gobiernos, en aras de la activación económica y de la efectiva utilización de la tierra bajo los lineamientos de la sostenibilidad y la viabilidad ambiental; como consecuencia de este anhelado desarrollo, se pretende reducir la pobreza mediante el fomento 
de la producción agrícola en términos de equidad y acompañamiento permanente del Estado colombiano; de la mano de esta pretensión, las actuaciones del gobierno Santos se orientarán hacia la titularización de las tierras en cabeza de los campesinos.

De este modo, el desarrollo agrario integral con enfoque territorial no consiste en una reforma agraria, no es redistribuir las tierras, consiste en la implementación de un modelo de gestión agrario que permita a los campesinos trabajar la tierra para promover la producción agrícola; consiste, además, en respetar los resguardos indígenas; $y$, conectar el trabajo de los campesinos con proyectos empresariales.

2. El establecimiento de garantías para el ejercicio de la oposición política y la participación ciudadana de los desmovilizados de la guerrilla de las FARC-EP. En este punto, los negociadores de ambas partes discutirán el texto de una posible reforma constitucional en materia de partidos políticos y de régimen electoral.

3. La finalización del conflicto armado, es decir, que cese el fuego; haya dejación de las armas; reinserción de los desmovilizados de las FARC-EP en los ámbitos económico, social, político y civil; y, la definición de la situación jurídica de los desmovilizados. En este numeral, tiene lugar la propuesta del gobierno Santos de establecer una justicia transicional.

4. El desmonte del negocio ilícito del narcotráfico. Para ello, el gobierno plantea la sustitución de los cultivos de drogas para la recuperación ambiental de los territorios afectados y fomentar el desarrollo rural integral agropecuario. Este punto guarda una estrecha relación con el primero de la agen$\mathrm{da}$, y se dirige a verificar el compromiso del grupo guerrillero con el anhelo de obtener la paz.
Sobre el flagelo del narcotráfico y su relación con el conflicto interno armado, se ha encontrado que es la fuente de financiación de la guerrilla de las FARC-EP, de los demás grupos guerrilleros y de las Autodefensas Unidas de Colombia. Se afirma, entonces, que las guerras son maquinarias económicas. En ese sentido, se acabó la guerra fría y a las guerrillas no les pasó nada, pues sus dinámicas económicas estaban relacionadas con las actividades del narcotráfico.

Como bien lo explica Mabel Londoño,

(...) hay un fenómeno que aparece como eje transversal tocando los intereses de los actores armados: el narcotráfico, pues el negocio de las drogas ilícitas logró permear la lucha guerrillera y se convirtió en el negocio de los paramilitares, conocidos hoy, luego del proceso de desmovilización realizado bajo el gobierno de Álvaro Uribe Vélez, con el nombre de bandas criminales 0 «Bacrim». Igualmente, trajo nuevos fondos para el sostenimiento de las clientelas políticas locales, en principio, y nacionales, en época posterior, lo que constituyó la criminalización de la vida política, fenómeno éste que se agravó bajo el gobierno del presidente Uribe (2012, p. 35).

5. Los derechos de las víctimas a la verdad. Frente a este numeral, se hace notoria la ausencia del componente del derecho a la reparación para las víctimas.

En consonancia con los puntos de la agenda, se resalta la necesidad de encontrar una solución definitiva al conflicto armado, que facilite la consolidación de un sistema de partidos políticos pluralista y realmente incluyente que fomente y fortalezca las estructuras democráticas del país.

De esta forma, en esta negociación entre el gobierno y las FARC-EP cabe formular la siguiente pregunta: ¿cuál es el costo político que asumirá 
el Estado de Colombia para la consecución de la tan anhelada paz?

Dar respuesta a este interrogante no es tarea fácil, pues en el marco de la solución del conflicto armado interno es de vital importancia no caer en la zona de la especulación; por el contrario, es fundamental confiar en el trabajo continuo, riguroso y serio de los miembros de las mesas de negociación y esperar que se obtengan acuerdos viables. Asimismo, es prioritario el respaldo de todos los sectores del país en el desarrollo de esta gran empresa para la paz.

Entrando al análisis de las actuales negociaciones, se reitera que los anteriores intentos frustrados de negociación con la guerrilla de las FARC-EP fueron realizados exclusivamente desde el aspecto político, sin tener en la cuenta el marco jurídico como medio para instrumentalizar los posibles acuerdos políticos en torno a los puntos neurálgicos para el cumplimiento de las agendas de paz.

Las vigentes negociaciones de paz con este grupo guerrillero responden a unos acercamientos políticos en aras a la firma de acuerdos referentes a los cinco puntos de la agenda anteriormente referenciados, que podrán ser regulados jurídicamente a través de una ley estatutaria como desarrollo del artículo 22 de la Constitución Política de 1991. Esta regulación jurídica es posible gracias a la expedición del Acto Legislativo 01 de 2012 (por medio del cual se establecen instrumentos jurídicos de justicia transicional en el marco del artículo 22 de la Constitución Política y se dictan otras disposiciones), reforma constitucional conocida en los medios de comunicación como el «marco jurídico para la paz».

De esta manera, las negociaciones conducentes a finalizar el conflicto interno colombiano con las FARC-EP se han caracterizado por la arrogancia de este grupo al margen de la ley; la indiferencia de la sociedad civil; y la soberbia de los gobiernos de los últimos cuarenta años en Colombia. Así pues, se evidencia la carencia de una política pública para la paz en el país, pese a la voluntad política, tanto del gobierno como del Congreso de la República en la elaboración de dicho acto legislativo.

En este contexto de solución al conflicto políti$\mathrm{co}$, se ha planteado la posibilidad de crear una justicia transicional para reducir la intensidad y la dinámica del conflicto que permita el paso de un Estado en vilo a un Estado sólido. Por consiguiente, no puede haber reconciliación sin paz y sin justicia, pues nada se lograría si las FARC-EP dejan las armas pero los crímenes cometidos quedan en la impunidad; y viceversa, nada se lograría si solamente se hace justicia pero el conflicto armado continúa. Tanto la paz como la justicia son las caras de una misma moneda.

Antes de continuar con el análisis de las dinámicas y los dilemas jurídicos que pueden presentarse en la aplicación de un régimen de justicia transicional, se hace necesario tener claridad sobre el concepto de este modelo excepcional de la justicia. Al respecto, se trae a colación:

La expresión justicia transicional se usa para designar aquellos procesos de rendición de cuentas que adelantan las entidades estatales en relación con crímenes políticos y de masas perpetrados en el pasado, en situaciones de turbulencia política como las que son propias de las transiciones de la guerra a la paz y de la dictadura a la democracia (Orozco, 2009, p. 9).

Según esta definición, se comprende que la justicia transicional hace referencia a aquellos procesos mediante los cuales se llevan a cabo transformaciones estructurales del sistema político, jurídico y social para solucionar los graves problemas de violencia; se trata entonces, para el caso colombiano, de una transición de la guerra a la paz en medio de un conflicto armado vigente.

Así las cosas, es necesaria la justicia transicional como excepción a la aplicación de la justicia or- 
dinaria en una situación temporal (transitoria) en la que los integrantes de un grupo al margen de la ley pasan de la vida delictiva a la vida civil. Entonces, en el marco de esta justicia se obtienen la reparación de las víctimas y la verdad mediante la rendición de cuentas, además de permitir la definición de la situación jurídica de los miembros de la guerrilla de las FARC-EP para ingresar a ejercer sin restricciones sus derechos políticos; se aprecia, pues, que la justicia fortalece el Estado Social de Derecho.

En síntesis, se quiere con el desarrollo de la agenda de paz solucionar los efectos de esta guerra civil, no aceptada por Colombia, mediante el establecimiento de medidas que garanticen la dejación de las armas, la reinserción, la reducción de la pobreza y la materialización de la justicia, la verdad y la reparación.

Al respecto, bajo el gobierno Uribe no se consideraba conflicto interno armado la lucha que se libraba en contra de la guerrilla de las FARCEP. En tal sentido, el conflicto armado se define como las estrategias bélicas e ideológicas dirigidas a tomar el poder por las vías armadas; tal cual se ha evidenciado durante las últimas décadas en el país, el ideal de lucha de las FARC-EP por la equidad y el beneficio del pueblo, fundamentos para su conformación, se perdieron con el paso de los años debido a la arrogancia, a la violencia y a los nexos con los narcotraficantes (Ferro, 2002). De ahí que el gobierno Uribe tildara a las FARC-EP de grupo narcoterrorista y, por tanto, afirmara que en Colombia no existía un conflicto interno.

Sobre el tema, Angarita manifiesta:

La guerrilla sostiene y promociona en el contexto internacional la idea que en Colombia existe un conflicto interno motivado por la lucha noble del pueblo en contra de los atropellos cometidos por las élites del país; por otro lado, el Gobierno Uribe sostenía que no existe un conflicto interno sino un narcoterrorismo (2012, p. 214).
Retomando el tema, se aprecia que las negociaciones que se realizan entre las mesas de trabajo del Gobierno y las FARC-EP en La Habana, en el evento de ser exitosas, se firmarían unos acuerdos políticos que deberán ser instrumentalizados durante un extenso período de tiempo que puede ir de cinco a quince años. En otras palabras, para la solución definitiva del conflicto se necesitará del compromiso de las partes para la implementación de estos acuerdos en normas jurídicas que respalden la formulación de las políticas públicas correspondientes.

No obstante, aunque el derecho esté regulando este proceso de paz, no es excusa para que las opciones y las estrategias políticas facilitadoras de estos diálogos se vean limitadas. Se observa, que el derecho atendiendo a su fin humano, debe adaptarse a las necesidades sociales y económicas de la actualidad para no obstaculizar las dinámicas políticas que facilitan la vida en sociedad y la búsqueda de una salida negociada del conflicto político histórico.

Finalmente, en el contexto político interno de Colombia, las colectividades políticas, los movimientos sociales, los sectores económicos, la academia, la ciudadanía, etc., no deben polarizarse afectando el proceso de paz; por el contrario, deben ellos debatir y proponer ideas que tiendan puentes entre las diferencias y permita encontrar la llave correcta para abrir la puerta de la paz.

\section{CONCLUSIONES}

Tanto el «rechazo a la violencia» como la voluntad de paz», han sido las constantes del pueblo colombiano frente a esta historia oscura y violenta que se ha caracterizado por albergar el conflicto armado interno más largo en la historia del mundo, cuyos orígenes van más allá del surgimiento de las guerrillas en 1964, las Fuerzas Armadas Revolucionarias de Colombia (FARC); Ejército Popular Liberal (EPL); y, el Ejército de Liberación Nacional (ELN), remontándose a los primeros días de vida republica- 
na desde las decenas de batallas libradas por la independencia, las guerras civiles, la Guerra de los Mil Días, hasta las confrontaciones ideológicas y armadas entre liberales y conservadores que atravesaron la historia política del país por casi dos siglos.

Según lo visto, teniendo presente que este artículo es un resultado parcial de una investigación (referenciada al inicio del texto), se encontraron los siguientes elementos de estudio que fundamentan y permiten el desarrollo satisfactorio de dicho proyecto:

1. Se determinó que en la década de los sesenta se crearon los grupos guerrilleros como reacciones, tanto hacia el sistema político excluyente que se gestó en el período del «Frente Nacional» como hacia la situación agraria que se agravó desde la década de los treinta. En consecuencia, se identificaron que entre las causas del conflicto armado interno de Colombia se encuentran la inequidad y la pobreza del país; la intolerancia política; la ausencia del Estado en muchas zonas del territorio nacional; y, la carencia de una política agraria de distribución de tierras destinadas al trabajo agrícola de los campesinos. En otras palabras, las causas de la conformación de grupos armados ilegales se reducen a las dinámicas que giran en torno al poder y a la tierra.

2. Se caracterizó la violencia política del país a partir de los sucesos más relevantes de la historia, con la finalidad de contextualizar y de comprender las actuales negociaciones de paz que se adelantan entre el gobierno Santos con la guerrilla de las FARC-EP en la ciudad de La Habana.

Así las cosas, las anteriores negociaciones eran exclusivamente políticas, sin un marco jurídico que facilitara la desmovilización, reinserción, judicialización y participación política de los actores políticos al margen de la ley. Las actuales negociaciones cuen- tan con un respaldo normativo que permite, entre muchos aspectos, un análisis riguroso orientado hacia la implementación de los acuerdos políticos mediante normas jurídicas; la aplicación de una justicia transicional; y, la participación de los desmovilizados en el escenario político-electoral.

Como resultado del análisis de estos diálogos de paz, se resaltó la utilización -como procedimiento de gestión en la labor del Estado colombiano-de una agenda concreta de cinco puntos en medio de la confrontación armada. En esta perspectiva, los voceros de ambas partes dialogan en medio de las hostilidades, el secuestro y la constante violación de los derechos humanos por parte de las FARC-EP.

Ante esta situación, se aplaudieron las pretensiones del gobierno Santos de buscar la solución al conflicto armado atendiendo a las estructuras del problema y, no a las manifestaciones coyunturales, en aras de la obtención de la paz en términos de ausencia de pugnas por el poder entre actores políticos divergentes.

3. Se afirmó, como condiciones para realizar las negociaciones dirigidas a obtener la paz, que este derecho fundamental tan anhelado se negocia desde la fortaleza del Estado; en este supuesto, la guerrilla está debilitada (pero no derrotada) y ha modificado sus estrategias orientándolas desde el plano de los diálogos para acceder al poder por la vía democrática, tal cual ha sucedido en el contexto internacional; así, las FARC$\mathrm{EP}$, se han dado cuenta de que las vías de las armas no conducen al poder.

4. Se precisó que la fase neurálgica de las actuales negociaciones será la denominada "postconflicto», pues requerirá que se materialicen los valores de la reconciliación y el perdón, condiciones sin las cuales no se puede crear una memoria histórica que sea vigía de la paz. 
Así mismo, en la fase del postconflicto cabe el siguiente planteamiento: ¿tanto el Estado como las FARC están preparados para pedir perdón? Sobre el asunto, es claro que, tanto el Partido Liberal como el Partido Conservador, no han pedido perdón por los miles de muertos a causa del conflicto político iniciado desde mediados del siglo XIX $y$, que se materializó en las 11 guerras nacionales y la Guerra de los Mil Días (la cual dejó la cifra de cien mil personas muertas). Además, se estima que a lo largo del siglo $\mathrm{XX}$, especialmente desde la segunda mitad de siglo, la violencia política entre ambas colectividades dejó a más de trescientas mil personas sin vida.

Finalmente, se dejan al lector los siguientes interrogantes a manera de reflexión: ¿Estará la guerrilla preparada para asumir responsabilidad política?; ¿está el país preparado para ver a los guerrilleros en los puestos públicos?; ¿están preparados los empresarios para dar trabajo a los desmovilizados de las FARC-EP?; ¿están preparadas las víctimas para encontrarse cara a cara con los victimarios?

\section{REFERENCIAS}

Arendt, H. (2009). Los orígenes del totalitarismo. Madrid: Alianza Editorial.

Angarita, P. \& Gallo, H. (2012). Discursos sobre el enemigo armado en Colombia, 1998-2009. En: Chambers, P. \& Espinal, V. Conflicto armado: interpretaciones y transformaciones. (pp. 211-238). Medellín: Universidad de Medellín.

Botero, A. (2003). La metodología documental en la investigación jurídica: alcances y perspectivas. En: Opinión jurídica: Revista de la Facultad de Derecho de la Universidad de Medellín, 4, julio-diciembre; 109 - 116.

Fals, O. Guzmán, G. \& Umaña, E. (2005). La violencia en Colombia, tomo 1. Bogotá: Taurus.
Ferro, J. \& Uribe, G. (2002). El orden de la guerra, las FARC-EP: entre la organización y la política. Bogotá: Centro Editorial Javeriano.

Hartlyn, J. (1993). La política del régimen de coaliciones, la experiencia del Frente Nacional en Colombia. Bogotá: Universidad de los Andes.

Hoyos, D. (2007). Evolución del sistema de partidos en Colombia (1972-2000) una mirada a nivel local y regional. En: Hoyos, D. Entre la persistencia y el cambio, 21-47. Bogotá: Editorial Universidad del Rosario.

Hoyos, D. (2009). Dinámicas político-electorales en zonas de influencia paramilitar. Análisis de la competencia y la participación electoral. En: Revista Análisis Político, 65, enero-abril, 13-32.

Joly, M. (2007). Diálogos en el infierno entre Maquiavelo y Montesquieu. México: Éxodo.

Legrand, C. (1986). Los antecedentes agrarios de la violencia: el conflicto social en la frontera colombiana, 1850-1936. (pp. 87-110). Bogotá: CEREC.

Londoño, M. (2012). El papel del juez en la democracia. Medellín: Universidad de Medellín.

Medina, C. (2010). FARC-EP y ELN. Una historia política comparada (1958-2006). Trabajo de grado presentado para optar por el título de Doctor en Historia. Bogotá: Universidad Nacional de Colombia, Facultad de Ciencias Humanas Departamento de Historia.

Mesa, D. 1972). El problema agrario en Colombia 1920 - 1960. Bogotá: Ediciones el Tigre de Papel.

Orozco, I. (2009). Justicia transicional en tiempos del deber de memoria. Bogotá: Temis.

Palacios, M. (2000). La Solución Política al Conflicto Armado, 1992-1997". En: Armar la Paz es Desarmar la Guerra. Camacho, Á. \& 
Leal, F. (Compiladores). (345-346). Bogotá: CEREC, DNP, FESCOL, IEPRI, Misión Social y Presidencia de la República.

Pécaut, D. (2001). Guerra contra la sociedad. Bogotá: Editorial Espasa.

Restrepo, L. (2006). Los arduos dilemas de la democracia en Colombia. En: Nuestra guerra sin nombre. Transformaciones del conflicto en Colombia. Bogotá: Norma, IEPRI y Universidad Nacional.

Romero, M. (2000). Democratización política y contrarreforma paramilitar en Colombia. En: Bulletin De L'Institut Francais D'Etudes Andines. 29, 3, 331-357.

Sánchez, G. (1983). Los días de la revolución: gaitanismo y 9 de abril en provincia. Bogotá: Centro Cultural Jorge Eliécer Gaitán.

Sánchez, G. \& Peñaranda, R. (1986). Pasado y presente de la violencia en Colombia. Bogotá: CEREC.
Sánchez, C. (2006). Derecho e instituciones electorales en Colombia. Bogotá: DIKE.

Tirado, A. (1998). Introducción a la historia económica de Colombia. Bogotá: El Áncora Editores.

Tirado, A. (2001). Del Frente Nacional al momento actual: diagnóstico de una crisis, Tomo II. Bogotá: Planeta.

Tirado, A. (2007). El Estado y la política en el siglo XIX. Bogotá: El Áncora Editores.

Uprimny, R. (2005). Justicia transicional en Colombia. Algunas herramientas conceptuales para el análisis del caso colombiano. En: Uprimny, R. \& Saffón, M. Justicia transicional sin transición. Extraído 30 de mayo de 2013 http://www.revistafuturos.info/download/ down_15/justiciaTransicional.pdf]

Uribe, M. (2002). "Las incidencias del miedo en la política: Una mirada desde Hobbes". En: Delumeau, J. et. al. El miedo. Reflexiones sobre su dimensión social y cultural. (pp. 25-46). Medellín: Corporación Región. 